\title{
TEORIA E CRISE
}

\author{
Marcelo Vasques Vedroni*
}

Resumo O presente artigo pretende retomar a análise teórica empreendida por Karl Marx sobre as crises capitalistas. Procurou-se, assim, identificar as leis fundamentais de movimento do capitalismo desenvolvidas por Marx em seus estudos, sendo a lei do valor aquela que comanda a produção e a acumulação capitalistas, quando há subsunção real do trabalho ao capital. Assim, identificou-se o objetivo real do capital, qual seja a valorização. Ocorre que ela depende de algumas condições, tais como o desenvolvimento máximo das forças produtivas. Ao desenvolver a tal ponto as forças de produção social, o capital acaba por dispensar trabalho vivo e tende à superprodução. Daí a possibilidade formal e real das crises, que são geradas no próprio movimento do capital e surgem periodicamente, de forma cíclica, e a análise da lei tendencial da queda da taxa de lucro como uma das principais formulações para se compreender os motivos de existência das crises capitalistas.

Palavras-chave crise; valorização; superprodução; taxa de lucro.

\section{THEORY AND CRISES}

Abstract This article intends to resume the theoretical analysis undertaken by Karl Marx on capitalist crises. Thus seek to identify the fundamental laws of motion of capitalism developed by Marx in his studies, and the law of value that controlling the production and accumulation capitalists when there real subsumption of labor to capital. Thus, we identify the real goal of the capital, which is the appreciation. It happens that the appreciation depends on several conditions, such as the maximum development of productive forces. In developing this point the forces of social production capital eventually dispense live work and tends to over-production. Then, there's the possibility of formal and actual crises. Such crises are generated in the movement of capital and appear periodically, in a cyclic. Then the analysis of law

* Mestre em Ciências Sociais pela Universidade Estadual de Londrina (UEL). Atualmente, é professor universitário nos cursos de graduação em Direito da Universidade Camilo Castelo Branco (Unicastelo) e nos cursos de graduação em Serviço Social e Pedagogia da Fundação Educacional de Fernandópolis (FEF). 
trend of falling profit rate as a major formulations to understand the reasons for the existence of capitalist crisis.

Keywords crisis; appreciation; recovery; overproduction; rate of profit.

\section{APRESENTAÇÃo}

No segundo semestre de 2008, a economia mundial foi acometida por uma crise de proporções tamanhas, e prontamente surgiram comparações com a famigerada crise de 1929. O financiamento sem controle nos mercados imobiliários norte-americanos, seguido da alta nas taxas de juros, impulsionou uma avalanche de insolvência que fez falir, em alguns dias, imensas fortalezas de capital financeiro acumulado. Tão logo a crise foi se desenrolando, surgiram inúmeros estudos sobre as causas, consequências e características de tamanho abalo na economia capitalista. Nesse ímpeto de se compreender o que estava havendo, as análises de Marx sobre o modo de produção capitalista submergiram, demonstrando sua atualidade e importância para o entendimento da realidade atual. Nessa ocasião, o célebre historiador inglês Eric Hobsbawm afirmou:

Há um indiscutível renascimento do interesse público por Marx no mundo capitalista, com exceção, provavelmente, dos novos membros da União Européia, do leste europeu. Este renascimento foi provavelmente acelerado pelo fato de que o $150^{\circ}$ aniversário da publicação do Manifesto Comunista coincidiu com uma crise econômica internacional particularmente dramática em um período de uma ultra-rápida globalização do livre-mercado (HoBSBAwn, 2012).

Tendo em vista esses pontos destacados, o objetivo aqui é retomar a análise teórica de Marx concernente ao entendimento das crises no modo de produção capitalista. Julga-se necessário debruçar-se sobre essa temática não pela discussão teórica em si, mas pelos indispensáveis instrumentos que são fornecidos para a compreensão sobre o movimento do capital em seu processo de produção e reprodução e para o entendimento do atual momento pelo qual passa a economia capitalista.

\section{AS LEIS DE MOVIMENTO DO CAPITAL}

Grande parte dos estudos de Marx tem como objetivo desvendar e compreender as leis imanentes ao modo de produção capitalista, as quais determinam o movi- 
mento do capital. Nesse contexto, ao realizar a crítica à economia política clássica, Marx discute as fontes e formas do valor, considerando a teoria do valor-trabalho de Ricardo ${ }^{1}$. Assim, é a lei do valor que vai determinar o movimento do capital em geral, porém, a seu modo, reconfigurada na forma de lei de valorização, a partir do momento em que há subsunção real do trabalho ao capital, que significa um momento histórico no qual o modo de produção capitalista alcança um avançado grau de desenvolvimento das forças produtivas. Nesse patamar, o capital passa a se fundamentar na utilização da mais-valia relativa, na qual a elevação da produtividade se obtém pelo incremento dos meios de produção. É nesse momento que a produção se torna especificamente capitalista.

A subsunção real do trabalho no capital desenvolve-se em todas aquelas formas que produzem mais-valia relativa, ao contrário de absoluta. Com a subordinação real do trabalho no capital efetua-se uma revolução total (que prossegue e se repete continuamente) no próprio modo de produção, na produtividade do trabalho. [...] Desenvolvem-se a forças produtivas sociais do trabalho e, graças ao trabalho em grande escala, chega-se à aplicação da ciência e da maquinaria à produção imediata (MARX, 2004, p. 104).

A utilização da máquina e a aplicação da ciência e da técnica permitem um ritmo acelerado de produção. O capital se torna, então, sujeito de um processo de produção cuja finalidade é a própria produção. É a ideia de produzir por produzir. Mas isso só faz sentido se o valor adiantado para a produção de mercadorias for instrumentalizado de tal modo que seja capaz de produzir um valor maior, acrescentado àquele do início do processo.

Para nosso capitalista, trata-se de duas coisas. Primeiro, ele quer produzir um valor de uso que tenha um valor de troca, um artigo destinado à venda, uma mercadoria. Segundo, ele quer produzir uma mercadoria cujo valor seja mais alto que a soma dos valores das mercadorias exigidas para produzi-la, os meios de produção e a força de trabalho, para as quais adiantou seu bom dinheiro no mercado. Quer produzir não só um valor de uso, mas uma mercadoria, não só valor de uso, mas valor e não só valor, mas também mais-valia (MARX, 1983, p. 155).

1 Em Miséria da Filosofia, Marx afirma: "o passo decisivo que é a aceitação da teoria do valor-trabalho e, em especial, do enfoque de Ricardo, diverso do de Smith no que se refere à determinação do valor pelo tempo de trabalho e não pelo “valor do trabalho” (MARX, 1982, p. IX). 
O objetivo fundamental da produção capitalista é produzir valor de troca para que possa haver valorização do valor adiantado. Nesse contexto, o valor de uso só é produzido pelo fato de carregar consigo um valor de troca e ser, assim, expressão material do valor. Esse objetivo se apresenta implícito no próprio conceito de capital e somente é obtido se o processo de produção for cada vez mais eficiente, produzindo mais produtos, valores de uso, com menor quantidade de trabalho necessário, imediato.

Produtividade do trabalho, em suma = máximo de produtos com mínimo de trabalho; daqui o maior embaratecimento possível das mercadorias. Independentemente da vontade deste ou daquele capitalista, isto converte-se na lei do modo de produção capitalista. E esta lei só se realiza implicando outra, a saber: a de que não são as necessidades existentes que determinam o nível da produção mas de que é a escala de produção - sempre crescente e imposta, por sua vez pelo próprio modo de produção - que determina a massa do produto. O seu objetivo (é) que cada produto etc. contenha o máximo possível de trabalho não pago, e isso só se alcança mediante a produção para a própria produção (MARX, 2004, p. 107-8).

Aqui Marx chama atenção para o objetivo do capital, qual seja a valorização. Não são as necessidades de consumo particulares, ou seja, não é a necessidade de consumo dos produtos que determinará o ritmo da produção. Este passa a ser determinado pela própria produção em si, transformando-se em produção que busca o valor de troca. A produção capitalista desenvolvida tem como objetivo não o valor de uso, as diferentes mercadorias disponíveis para consumo dos indivíduos, mas sim o valor de troca. Em Teorias da mais-valia, Marx reafirma o propósito máximo do capital. Explica:

[...] o objetivo direto da produção capitalista não é o valor de uso, mas o valor de troca e em especial incremento da mais-valia. Este é o motivo que impulsiona a produção capitalista, e é um primor de concepção a que, para escamotear as contradições da produção capitalista, omite-lhe a base e faz dela uma produção dirigida para o consumo imediato dos produtores (MARX, 1980, p. 931)².

2 [...] o objetivo da produção capitalista não é apossar-se de outros bens, e sim apropriar-se de valor, de dinheiro, de riqueza abstrata (MARx, 1980, p. 939). 
Nesse nível de desenvolvimento das forças produtivas no qual há subsunção real do trabalho perante o capital, este pôde adquirir uma autonomia tal que se desvencilhou de quaisquer limites externos à sua reprodução continuada. Grespan vê nesse fato a ideia de desmedida e infinitude do movimento do capital. Afirma que o capital não encontra

Fora de si mais nenhum limite permanente, nenhum elemento exterior que lhe possa conter indefinidamente a expansão, já que esta se baseia no domínio da fonte de valor mesma. [...] O primeiro significado de "desmedida”, específica do movimento de acumulação do capital portanto, vem da infinitude deste movimento. [...] Não há, por princípio, uma referência externa ao capital para determinar a magnitude de sua acumulação. Ele tem essencialmente em si a sua medida [...]. É claro que Marx considera também os obstáculos e as condições existentes para a acumulação. Mas lhe interessa enfatizar que da natureza do capital surge o impulso para a superação destes obstáculos, impulso, assim, inerente e necessário àquela natureza (GRESPAN, 1998, p. 129-30).

Nesse sentido, ao mesmo tempo em que o capital se liberta de limites externos à sua reprodução e expansão, afirma seu caráter contraditório, ao esbarrar em obstáculos gerados por seu próprio movimento. O capital põe a si mesmo entraves e dificuldades a seu movimento de produção e reprodução.

\section{AS CONDIÇÕES PARA A VALORIZAÇÃO}

Para poder atingir seu principal objetivo, a valorização, o capital tem, obrigatoriamente, que criar uma base técnica adequada para se reproduzir de forma constante. Assim, procura desenvolver ao máximo as forças produtivas sociais, o que permite explorar cada vez mais trabalho vivo e, consequentemente, diminuir o tempo de trabalho necessário para a produção de mercadorias. Marx chega a afirmar: "O desenvolvimento das forças produtivas do trabalho social é a tarefa e justificativa histórica do capital” (MARx, 1988, p. 186).

Nessa tarefa, portanto, o capital tem a oportunidade de elevar o tempo de trabalho não pago e, por isso mesmo, extrair mais mais-valia por meio da exploração do trabalho. A propósito desse movimento, Mazzuchelli afirma tratar-se de lei imanente ao modo de produção capitalista, pois 
[...] a valorização máxima supõe a apropriação máxima de trabalho não-pago, que implica o desenvolvimento máximo das forças produtivas e, portanto, a acumulação máxima. A "produção pela produção", a tendência ao "desenvolvimento absoluto das forças produtivas", a "acumulação progressiva" constituem, assim, uma lei imanente do regime de produção capitalista, no sentido de que se deduzem e se adéquam ao conceito mesmo de capital, enquanto valor que se valoriza através da apropriação de trabalho não-pago (MAZzUCHELLI, 1985, p. 20).

Ocorre que o desenvolvimento máximo das forças produtivas na busca pela superação dos limites da produção capitalista não é um processo infinito ou ilimitado. É, antes, histórico e tem por base determinadas condições históricas para se desenvolver e se consolidar. O fato de não encontrar limites externos a seu movimento expansivo é contraditoriamente refutado pelo fato de que o limite à produção capitalista passa a ser o próprio capital. Nesse sentido, o capital põe a si mesmo barreiras que devem ser superadas se a intenção for manter seu ritmo de exploração do trabalho e de acumulação.

Ao desenvolver as forças produtivas sociais, o capital cria uma base técnica específica na qual o aumento da apropriação de trabalho não pago se torna possível e viável. Para tanto, utiliza-se da exploração do trabalho na forma de mais-valia relativa. Com isso, o quanto de capital constante (meios de produção) em cada capital individual tende a aumentar em relação ao capital variável (trabalhadores produtivos). Nesse momento há uma elevação da composição orgânica do capital, a qual se reflete na negação do trabalho vivo.

O capital nega trabalho vivo, no entanto, sendo o trabalho vivo a única fonte de valor, o capital acaba por negar, contraditoriamente, seu principal instrumento para a valorização. $O$ trabalho vivo, imediato, é fonte de valor, mas é contraditoriamente negado, dispensado pelo capital, o qual se desenvolve de forma contraditória, já que coloca constantemente a si mesmo, em seu movimento de produção e reprodução, contradições que devem ser superadas a todo o momento. Como afirma Mazzuchelli (1985, p. 22):

[...] a valorização do valor pressuposto, ao redundar na autonomização da produção pela produção, implica, contraditoriamente, a tendência recorrente do capital a se abstrair das determinações de sua valorização e, portanto, das determinações da própria produção de valores. [...] é neste sentido que o capital contém em si mesmo a tendência à superprodução e à negação do trabalho imediato. 
Aqui, o objetivo primeiro do capital, o da valorização, é forçado a se realizar em uma base cada vez mais estreita. A negação do trabalho vivo implica uma dificuldade cada vez maior para a valorização, visto que, como será explicado mais adiante, a tendência à elevação da composição orgânica do capital dificulta e faz cair a taxa de lucro.

À elevação da composição orgânica do capital corresponde uma diminuição do tanto de trabalho vivo empregado na produção, e, nesse sentido, é nesse momento que o capital abstrai as determinações de sua valorização. Nesse contexto, as crises de sobreacumulação e superprodução, manifestações violentas da dificuldade imposta para a realização do valor, aparecem como resultado do próprio movimento do capital.

\section{POSSIBILIDADE FORMAL DA CRISE}

É relevante apontar que Marx não apresenta um conceito único acerca das crises capitalistas. No interior de sua obra, mais especificamente em $O$ capital e Teorias da mais-valia, o conceito de crise aparece disperso, de modo que pode ser definido no decorrer das explicações sobre as contradições do capital.

Ao se elevar do abstrato para o concreto, Marx demonstra desde as contradições mais abstratas do capital, como a oposição interna da mercadoria, até as formas mais concretas de aparecimento dessas contradições, como no crédito e na concorrência.

As crises capitalistas são produtos do próprio movimento do capital, no sentido de que é o próprio capital que, por meio de suas contradições, traz consigo as condições para as crises. Primeiramente, essas condições se apresentam como uma possibilidade formal, como crise em potência, pois a metamorfose da mercadoria enseja a forma para essa possibilidade.

Por sua vez, a possibilidade de crises se encontra implícita, então, no próprio conceito de capital como valor que se valoriza e que, para tanto, deve percorrer um processo de metamorfose contínua da mercadoria. Nesse processo, o valor se manifesta em diferentes formas: ora como mercadoria, ora como dinheiro.

Em sua obra Teorias da mais-valia, Marx analisa o fenômeno das crises capitalistas; primeiramente, como essa possibilidade acaba se tornando realidade. Afirma que "a dissociação entre o processo de produção e o processo de circulação evidencia e desenvolve mais a possibilidade de crise [...]" (MARX, 1980, p. 931). Isso ocorre, pois, no movimento de valorização que acontece na produção, e o capital se converte da forma dinheiro à forma mercadoria. Para que se complete 
o ciclo de valorização, a mercadoria, por sua vez, tem de se reconverter na forma dinheiro, por meio de sua venda. É justamente se reconvertendo em dinheiro que o movimento de valorização pode se completar, mas, para isso, a mercadoria deve ser vendida, pois só assim ela se reconverte em dinheiro.

Nesse sentido, o processo de circulação no qual se insere a venda da mercadoria tem de se completar para que não seja dissociada a unidade entre produção e circulação do capital, expressão mais concreta da oposição entre valor de uso e valor de troca identificada na mercadoria.

Para cumprir esse processo de metamorfose, de manifestação do valor na forma de mercadoria e na forma de dinheiro (D - M - D'), é necessário percorrer etapas que se apresentam no interior de uma unidade e, por isso, são complementares. Porém,

[...] apesar dessa unidade intrínseca necessária, são por igual partes e formas independentes do processo, contrapostas em sua existência, discrepantes no tempo e no espaço, separáveis e separadas uma da outra. A possibilidade da crise reside apenas na dissociação entre compra e venda. [...] se compra e venda coincidissem, deixaria de haver, de acordo com as suposições feitas, a possibilidade de crise (MARx, 1980, p. 944).

Com isso, Marx quer demonstrar que a possibilidade de crise se encerra na própria metamorfose da mercadoria, que se expressa no ciclo produtivo no qual o dinheiro se converte na forma mercadoria, e esta, por sua vez, deve se reconverter na forma dinheiro. A mercadoria deve se reconverter em um valor expresso em dinheiro que seja mais elevado que o valor inicialmente aplicado.

Nesse processo, o ciclo pode sofrer rupturas e ter suas fases complementares dissociadas, pois o dinheiro, em sua atuação como meio de pagamento, permite que essas fases se autonomizem, dando ensejo à interrupção do movimento de valorização do capital. Por isso, o que deveria permanecer em unidade para completar um processo, um ciclo, é violentamente separado. Nesse contexto, as crises capitalistas se manifestam, então, como produto da interrupção do movimento de valorização do capital. Nas palavras de Marx, a crise vem a ser "a imposição violenta da unidade das fases do processo de produção, as quais se tornaram independentes uma da outra” (MARX, 1980, p. 945).

\section{O DINHEIRO}


Os momentos de compra e venda podem ser separados no tempo e, assim, fazer com que o processo de valorização do capital seja interrompido, quando interrompida a metamorfose da mercadoria. Cabe enfatizar que a existência do dinheiro como meio de pagamento possibilita a paralisação do movimento de compra e venda, fato que não aconteceria na troca direta entre valores de uso. $\mathrm{Na}$ troca direta entre produtos, o objetivo seria adquirir um valor de uso, uma utilidade. Na produção capitalista desenvolvida, o objetivo é o valor de troca na forma dinheiro, sendo este "única existência adequada do valor de troca perante todas as demais mercadorias, enquanto simples valores de uso" (MARX, 1983, p. 110).

Ocorre que o dinheiro como forma de manifestação do valor não carrega consigo qualquer materialidade, sendo pura forma. Como tal, destituído de materialidade, o dinheiro pode interromper uma troca mercantil, uma transação de compra e venda, pois seu uso como meio de pagamento, vale dizer, o uso do dinheiro como dinheiro, não requer que haja uma materialidade por trás do valor. Nesse sentido, o valor na forma de dinheiro é mera forma vazia, sem conteúdo3.

Compra e venda são duas fases de um processo unívoco e complementar que, não obstante, pode ser interrompido por um período de tempo. Isso é possível tendo em vista que o movimento do capital em seu processo de valorização torna necessário transformar mercadoria em dinheiro e, por isso, a utilização de dinheiro na compra de mercadorias.

A dificuldade de transformar a mercadoria em dinheiro, de vender, provém apenas de a mercadoria ter de se transformar em dinheiro, sem o dinheiro ter de imediato de se converter em mercadoria, e de compra e venda poderem dissociar-se (MARX, 1980, p. 945).

Verifica-se que há possibilidade de interrupção do necessário movimento de metamorfose da mercadoria, tendo em vista que há possibilidade de que o valor apresentado na forma de mercadoria não se reconverta na forma dinheiro. Nesse caso, o capital não realiza a mais-valia, e as crises surgem como manifestação desse problema, pois o lucro não pode ser obtido.

3 Sobre dinheiro na atualidade, Paulani analisa a realização plena de seu conceito como forma do valor. Nesses termos, afirma: "É só nos marcos de um regime monetário como o atual, inteiramente fiduciário e com câmbio flexível, que o dinheiro pode realizar plenamente sua essência descarnada. Se, como adiantou Marx, o espaço mundial é o lócus em que o dinheiro ganha uma forma de existência adequada a seu conceito, é só com sua desvinculação do ouro que ele ganha uma matéria (a forma pura) capaz de realizar plenamente essa existência” (PAULANI, 2000, p. 105-6). 
Em Marx, o dinheiro aparece como resultado do desenvolvimento histórico da troca e para que os produtos dos trabalhos individuais se tornem mercadorias mercantilizadas. Esse processo faz do dinheiro forma independente e autônoma do valor das mercadorias. O valor passa a ser expresso pela forma dinheiro e põe na circulação a oposição encoberta no interior da mercadoria entre valor de uso e valor. Conforme explica Marx (1988, p. 63):

A antítese interna entre valor de uso e valor, oculta na mercadoria, é, portanto, representada por meio de uma antítese externa, isto é, por meio da relação de duas mercadorias, na qual uma delas, cujo valor deve ser expresso, funciona diretamente apenas como valor de uso; a outra, ao contrário, na qual o valor é expresso, vale diretamente apenas como valor de troca.

A oposição interna e oculta na mercadoria entre valor de uso e valor de troca se manifesta, na realidade, de modo mais concreto na oposição entre mercadoria e dinheiro. É aí que o desenvolvimento da produção capitalista faz com que a forma passe a ganhar conteúdo, para que a circulação do capital possa funcionar. O dinheiro passa a atuar, então, como expressão concreta do valor.

A ampliação e aprofundamento históricos da troca desenvolvem a antítese entre valor de uso e valor latente na natureza da mercadoria. A necessidade de dar a essa antítese representação externa para a circulação leva a uma forma independente do valor da mercadoria e não se detém nem descansa até tê-la alcançado definitivamente por meio da duplicação da mercadoria em mercadoria e em dinheiro (MARX, 1988, p. 81).

O dinheiro é a mercadoria na qual todas as outras se fundamentam para medir seus valores. Essa função surge para o dinheiro conforme a contradição interna da mercadoria valor de uso/valor de troca se exterioriza no processo de troca, na circulação do capital. Nesse processo, há a ocorrência de dois momentos que, não obstante serem complementares, podem ser dissociados pelo dinheiro.

Marx visualiza na circulação do capital o processo de metamorfose das mercadorias ocorrido na troca por meio da equação $\mathrm{M}-\mathrm{D}-\mathrm{M}$. Nela se pode visualizar o primeiro movimento como $\mathrm{M}$ - D (venda), troca de mercadoria M por dinheiro D; e o segundo movimento D - M (compra), troca de dinheiro D por mercadoria M. Esse processo, que poderia se completar de uma só vez, de forma simultânea, pode ser separado no tempo ou ter seus momentos interrompidos com o uso do 
dinheiro como meio de pagamento, não obstante serem uma unidade que carrega em seu interior duas fases complementares.

A primeira metamorfose de uma mercadoria, sua transformação da forma mercadoria em dinheiro, é sempre, simultaneamente, a segunda metamorfose inversa de outra mercadoria, sua retransformação da forma dinheiro em mercadoria (MARX, 1988, p. 97).

Na equação $\mathrm{M}$ - D - M, venda e compra são dois atos que relacionam duas pessoas e as colocam em oposição, sendo estas o possuidor de mercadoria e o possuidor de dinheiro. Assim, é possível que ocorra um intervalo no interior do processo pelo fato de que o possuidor de dinheiro pode decidir não realizar uma compra, mesmo tendo efetuado uma venda, já que "Ninguém pode vender sem que outro compre. Mas ninguém precisa comprar imediatamente apenas por ter vendido" (MARX, 1988, p. 100).

A unidade interna da mercadoria é desfeita por meio de uma antítese externa, na qual os processos se autonomizam. A contradição encontrada no interior da mercadoria se manifesta nas formas desenvolvidas da troca. É dessa dedução das formas da mercadoria, do movimento de metamorfose da mercadoria, quando há produção especificamente para a troca, que Marx demonstra a possibilidade de crises. Assim, essa possibilidade está no interior do modo de produção capitalista, e o capital traz consigo as possibilidades e as condições para as crises.

\section{AS CONDIÇÕES GERAIS DA CRISE: DA POSSIBILIDADE PARA A REALIDADE}

Toda essa análise conceitual deve ter por complemento compreender o movimento real do capital em contraposição à análise meramente formal da crise. Até aqui, há apenas a forma que permite a manifestação de um conteúdo.

A possibilidade geral das crises é a metamorfose formal do próprio capital, a dissociação da compra e venda no tempo e no espaço. Mas esse processo nunca é a causa da crise, pois é apenas a forma mais geral da crise, isto é, a própria crise em sua expressão mais geral. Não se pode dizer que a forma abstrata da crise é a causa da crise. Quem pergunta por sua causa, quer saber precisamente por que sua forma abstrata, a forma de sua possibilidade, passa da possibilidade para a realidade (MARX, 1980, p. 950). 
Nessa passagem, Marx chama a atenção para o fato de que a investigação deve avançar para além das formas e, assim, poder apreender seu conteúdo. Esse é o caminho no qual se eleva do abstrato para o concreto. Aqui eis a forma, pura abstração. Cabe, portanto, compreender como a possibilidade geral das crises se efetiva na realidade e se manifesta no modo de produção capitalista, pois “[...] o meio por que essa possibilidade de crise se torna a crise não se contém nessa própria forma; esta implica apenas em que existe a forma para uma crise" (MARX, 1980, p. 945).

A forma que possibilita o surgimento das crises está implícita no próprio modo de ser do capital, em suas leis fundamentais de existência. Seu movimento de metamorfose em mercadoria e em dinheiro revela a unidade contraditória identificada no interior da mercadoria, a qual carrega consigo a contradição percebida na oposição produzida por seu duplo caráter de valor de troca e de uso. A contradição abstrata entre valor de troca e de uso se manifesta na contradição, um pouco mais concreta, entre dinheiro e mercadoria. A forma dinheiro, como expressão do valor de troca, permite que a venda de uma mercadoria não se efetue e, por isso, a reconversão da forma mercadoria em forma dinheiro fica prejudicada. A produção mercantil tem por finalidade a produção de valores de troca, e, por isso, a conversão da mercadoria em dinheiro se torna o objetivo primeiro, sem o qual a possibilidade de crise torna a crise realidade.

Podemos portanto dizer: em sua primeira forma, a crise é a metamorfose da própria mercadoria, a dissociação da compra e venda. Em sua segunda forma, a crise é a função do dinheiro como meio de pagamento, e então o dinheiro figura em duas fases diferentes, separadas no tempo, em dois papéis diversos. As duas formas ainda são de todo abstratas, embora a segunda seja mais concreta que a primeira (MARX, 1980, p. 945).

Nesse sentido, a crise é possível pelo fato de que o capital é obrigado a percorrer um movimento de metamorfose para se valorizar, porém esse movimento pode ser interrompido a qualquer momento, em decorrência do uso do dinheiro como meio de pagamento, que se autonomiza de tal forma que pode se retirar momentaneamente da circulação. Isso se explica tendo em vista que, para Marx, a função do dinheiro como meio de pagamento se define por sua condição de realizar pagamentos diferidos, com prazo de vencimento que não o exato momento da compra. Diferentemente dos pagamentos à vista, em que o dinheiro funciona como meio de circulação, na função de meio de pagamento, o dinheiro pode se ausentar por 
um momento da transação, até que vença o prazo para o pagamento. Na ocasião em que não executa o pagamento no prazo estipulado, o dinheiro "não retorna" à circulação, e a metamorfose da mercadoria, vale dizer, a reconversão da mercadoria em dinheiro, não se realiza. Nesse momento, a mais-valia não se realiza, o valor não se realiza, e não pode haver valorização.

Tendo isso em vista, é relevante salientar que o dinheiro permite a interrupção do processo, pois, além de meio de pagamento, tem condição de cumprir a função de elemento de entesouramento, ao se ausentar da circulação. Nesse momento, "o dinheiro petrifica-se, então, em tesouro e o vendedor de mercadorias torna-se entesourador" (MARX, 1988, p. 111). O dinheiro passa a ser elemento que se autonomiza perante a troca e atinge um nível de independência tal que se autonomiza em relação a todo o processo. Passa mesmo a determiná-lo e, determinando seu movimento, dita sua pausa e sua continuação. Contudo, cabe enfatizar que o dinheiro nessa função de meio de pagamento acaba por implicar uma contradição, sendo que "essa contradição estoura no momento de crises comerciais e de produção a que se dá o nome de crise monetária” (MARX, 1983, p. 116).

Tendo isso em vista, a análise até aqui se concentrou no movimento de metamorfose do capital, nas formas como o valor se reveste. Ocorre que essas formas não são vazias, pois, em realidade, manifestam um conteúdo. Assim, a investigação teórica necessita elevar-se do abstrato para o concreto, sendo forçoso passar para a análise do processo real de produção capitalista, no qual há exploração de trabalho, crédito e concorrência. Nesse ponto, as formas do valor adquirem substância, que se manifesta na realidade.

Assim, ao observarmos o processo de reprodução do capital (o qual coincide com a circulação dele) cabe, antes de mais nada, demonstrar que aquelas formas apenas se repetem ou antes só aí adquirem um conteúdo, um fundamento que lhes permite se manifestarem (MARX, 1980, p. 945-6).

As contradições do capital aparecem na realidade preenchendo a forma que confere condições a que elas se manifestem. O modo como aparecem é histórico, determinado pelas condições históricas concretas pelas quais passa a economia capitalista, com o desenvolvimento das forças produtivas e das forças sociais em luta. A produção e a circulação do capital respeitam as condições históricas a que estão submetidas, mas, não obstante, as leis que regem a existência e o funcionamento do capital podem ser percebidas a qualquer tempo. Os fundamentos do modo de produção capitalista se mantêm atuais e aparecem nas variadas formas 
que a produção e a circulação do capital determinam. Concentração e centralização do capital, capital financeiro, padrão dólar-dólar são fenômenos que apenas corroboram, na concreticidade, as formas de manifestação das condições de existência do capital.

O conteúdo a ser manifestado pelo movimento do capital, ou seja, o fundamento real e não apenas formal da possibilidade das crises, pode ser encontrado na circulação do capital, onde há a atuação do dinheiro como meio de pagamento. É nessa função de meio de pagamento que o dinheiro permite a dissociação entre compra e venda.

Compra e venda se tornam a manifestação da metamorfose da mercadoria, no sentido de que, pela compra, o capitalista adquire os elementos do capital constante, ou seja, os meios de produção necessários à produção de uma mercadoria. Por meio do consumo produtivo dos meios de produção, há a conversão do dinheiro em mercadoria, já que ali foi produzida uma mercadoria, um valor de uso. Agora, é chegado o momento de reconverter essa mercadoria em dinheiro e reconverter um valor de uso em valor de troca, sendo que este, por sua vez, deve representar um valor já valorizado. Isso ocorre por meio da venda da mercadoria, expressão concreta da realização da mais-valia. Esse processo de produção e reprodução do capital deve ser repetido continuadamente. Desse modo,

[...] uma mercadoria se converte em dinheiro porque outra se reconverteu da forma dinheiro em mercadoria. Assim, a dissociação da compra e venda aparece aí de modo que à conversão de um capital, da forma mercadoria para a forma dinheiro, tem de corresponder a reconversão de outro capital, da forma dinheiro para a forma mercadoria; a primeira metamorfose de um capital tem de corresponder à segunda do outro, e a saída de um capital do processo de produção, à volta do outro a esse processo (MARX, 1980, p. 946).

Se o capitalista que comprou os meios de produção não conseguir vender a mercadoria por ele produzida, ou seja, não conseguir reconverter a mercadoria em dinheiro, não terá condições de pagar a compra dos meios de produção por ele utilizados. Consequentemente, o produtor daqueles meios de produção não poderá pagar a compra dos insumos utilizados para produzi-los. Isso ocorre, pois, "uma vez que aí a mesma soma de dinheiro funciona para uma série de transações e operações recíprocas, há insolvência não só num ponto, mas em muitos. Daí a crise" (MARx, 1980, p. 949). A insolvência se generaliza e, então, uma crise está instalada na economia. Os capitalistas não conseguem dar continuidade à produção e, por isso, 
[...] todos eles, que não realizam o valor de sua mercadoria, não podem substituir a parte que repõe o capital constante. Surge assim crise geral. Isso nada mais é que o desenvolvimento da possibilidade da crise no caso do dinheiro como meio de pagamento, mas aí já vemos, na produção capitalista, uma conexão entre os créditos e obrigações recíprocas, entre as compras e vendas, quando a possibilidade pode converter-se em realidade (MARX, 1980, p. 947).

Percebe-se que as condições para as crises estão inscritas no próprio movimento do capital, na própria metamorfose da mercadoria como movimento necessário à realização do capital. À reprodução das condições de produção capitalista como produção para a valorização corresponde uma base já desenvolvida em um patamar que permite ao dinheiro se autonomizar e, consequentemente, dissociar a unidade entre compra e venda. É na circulação desenvolvida do capital, no momento em que se desenvolvem o crédito e a concorrência, que o ambiente propício para as crises pode ser contraditoriamente desenvolvido pelo próprio capital. Nesse sentido, é com o desenvolvimento das condições propícias para a valorização do capital que se processam ao mesmo tempo, e de forma contraditória, as condições que dificultam sua valorização. E as condições para a valorização do capital determinam que a produção tenha como objetivo final o valor de troca. Nesse caso, o dinheiro aparece como expressão do valor. Ao fim de cada ciclo de produção, a mercadoria produzida deve ser vendida para que o valor seja reconvertido na forma dinheiro.

Deve-se ressaltar que o capital, como algo que se valoriza e, para tanto, tende necessariamente a desenvolver ao máximo as forças produtivas a ponto de chegar a "produzir por produzir", ultrapassa constantemente seus limites, sua base estreita na qual se apoia para se valorizar.

O afã desmedido de apropriação da mais-valia relativa se choca, assim, com a tendência à "supressão" do trabalho necessário [...]. Mas não é apenas o trabalho necessário que tende a ser suprimido: na medida em que a finalidade do capital é a de "dar à produção um caráter científico", reduzindo o trabalho "a um mero momento desse processo", é o próprio trabalho que se torna progressivamente redundante para os fins da produção capitalista. E isto envolve uma abrupta contradição, já que o capital tende a negar a base sobre a qual se apóia a produção de valores e, portanto, a própria valorização (MAZzUCHELLI, 1985, p. 33). 
Ao suprimir trabalho necessário na produção, o capital faz aumentar sua produtividade. Agora, mais produto é produzido com o mesmo quantum ou uma quantidade menor do trabalho que era anteriormente necessário. Isso é possível, como já dito antes, com a utilização da técnica e da ciência na produção, as quais permitem a utilização de meios de produção cada vez mais produtivos e "poupadores de trabalho vivo". Com isso, a extração de mais-valia relativa, a produtividade do trabalho e a acumulação se tornam potencializadas e aceleradas.

Porém, ao dispensar trabalho vivo, imediato, o capital acaba por elevar relativamente sua composição técnica (meios de produção), e esse fato, por consequência, acaba por elevar a composição orgânica do capital (elevação no valor do capital constante). Mesmo que haja uma diminuição no valor do trabalho vivo empregado (capital variável), há uma elevação absoluta da composição orgânica do capital puxada pelo aumento do capital constante.

Desse modo, “cai a taxa de lucro, porque o valor do capital constante subiu em relação ao do variável e se emprega menos capital variável” (MARX, 1980, p. 951). Essa é, em realidade, a condição para a crise. Mas aqui se trata da crise no nível da produção capitalista, e não mais no nível das formas do capital, em sua metamorfose processual. Desse raciocínio depreende-se uma das leis imanentes à produção capitalista, lei essa que caracteriza uma tendência no movimento da produção, qual seja a chamada lei da queda tendencial da taxa de lucro.

\section{A LEI DA QUEDA TENDENCIAL DA TAXA DE LUCRO}

A lei de tendência à queda das taxas de lucro é um dos importantes elementos teóricos desenvolvidos por Marx. Demonstra que a queda das taxas de lucro como tendência histórica da economia capitalista não surge por fatores exteriores ao capital, ou seja, não se trata de nenhum fato ou acidente externo à produção capitalista. É, sim, proveniente das contradições que se encontram na natureza mesma do modo de produção capitalista.

Paulani, em artigo para o seminário virtual "Marxismo e século XXI" (2009), organizado pelo portal eletrônico Carta Maior, interpreta essa questão afirmando que as crises capitalistas não expressam uma falha no movimento do capital, mas, pelo contrário, são necessárias para manter viva a atividade do capital. Entende que:

Bem ao contrário do que postula a economia convencional, para a qual o estado normal da economia capitalista é a harmonia e o equilíbrio, sendo as crises momentos incomuns, rapidamente corrigidos se o mercado for deixado em paz, 
Marx enxerga nesses eventos a característica definidora do capitalismo. Vendo-o como um sistema complexo e dinâmico, movido a contradições, esses episódios são, para ele, tão naturais quanto necessários. Na visão de Marx, a crise é o momento em que as contradições se materializam e exigem solução, sob pena de se comprometer a viabilidade do sistema. A causa das crises é sempre o excesso de acumulação de capital, que, a partir de determinado momento, não encontra condições de se realizar. Ao permitir a queima de capital, as crises liberam o espaço para a continuidade do processo de acumulação (PAULANI, 2009a).

Paulani afirma serem as crises característica natural de um sistema movido a contradições. Mas, além disso, enxerga nas crises um recurso momentâneo para solucionar as interrupções, no movimento de valorização do capital. As contradições se manifestam concretamente na forma de crise, pois esse é o modo como o capital tem condições de solucionar o problema da baixa nas taxas de lucro. De tempos em tempos, o capital acumulado em excesso não tem condições de se realizar. A valorização do capital fica assim interrompida, e as crises aparecem como solução violenta a esse fenômeno.

O desenvolvimento das forças produtivas sociais faz com que, no interior da produção, o valor do capital constante se eleve proporcionalmente mais que o valor do capital variável. O resultado disso é uma elevação da composição orgânica do capital, e o valor do capital constante empregado cresce em relação ao capital global adiantado, e isso se reflete na queda da taxa de lucro.

[...] ocorre um decréscimo relativo do capital variável em relação ao capital constante e, com isso, em relação ao capital global posto em movimento. Isso só quer dizer que o mesmo número de trabalhadores [...] põe em movimento, processa e consome produtivamente ao mesmo tempo uma massa sempre crescente de meios de trabalho [...], portanto, também um capital constante de volume de valor sempre crescente (MARX, 1988, p. 154-55).

Nessa passagem, pode-se perceber que o movimento de valorização, objetivo primeiro do capital, leva o conjunto dos capitalistas a elevarem a composição orgânica do capital. Para alcançar maior produtividade, o capital procura fazer com que um mesmo número de trabalhadores possa produzir cada vez mais produtos. O valor embutido em meios de produção, capital constante, cresce em relação ao valor do capital variável. Nesse momento, o trabalho vivo, fonte de valor, é negado. 
Marx explica o lucro como excedente de valor obtido por meio da extração da mais-valia. Por meio desse recurso, é gerado um valor que “[...] está, portanto, numa relação com o capital global, que se expressa na fração $\frac{\mathrm{m}}{C}$, em que $C$ representa o capital global” (MARx, 1988, p. 32). À medida que se eleva o valor da composição orgânica do capital, eleva-se o valor do capital global $C$, e, consequentemente, a taxa de mais-valia expressar-se-á em uma taxa de lucro em queda.

[...] o progressivo decréscimo relativo do capital variável em relação ao capital constante gera uma composição orgânica crescentemente superior do capital global, cuja conseqüência imediata é que a taxa de mais-valia, com grau constante e até mesmo crescente de exploração do trabalho, se expressa numa taxa geral de lucro em queda contínua (MARX, 1988, p. 155).

A lei tendencial da queda da taxa de lucro reflete, assim, o quão contraditório é o movimento do capital. Para lograr aumentar a exploração do trabalho via mais-valia relativa, e, desse modo, elevar o tempo de trabalho não pago, o capital utiliza elementos que se transformam em verdadeiras barreiras para a elevação da taxa de lucro. Sendo ela inversamente proporcional à composição orgânica do capital, a elevação desta por consequência da elevação do valor do capital constante gera uma queda da taxa de lucro, que se transforma em verdadeira tendência na economia capitalista, à medida que se generaliza na produção capitalista.

Nesse ponto, quando, apesar de todo o esforço capitalista em ampliar e acelerar a produção, seu lucro passa a não ser satisfatório, o capital encontra seu algoz, que, paradoxalmente, é ele mesmo, o próprio capital, o ser que impõe limites a si mesmo. O capital é seu próprio limite e traz consigo as barreiras as quais tem de suplantar. Traz em si mesmo os elementos que o leva à crise, já que

[...] o desenvolvimento da força produtiva de trabalho gera, na queda da taxa de lucro, uma lei que em certo ponto se opõe com a maior hostilidade a seu próprio desenvolvimento, tendo de ser portanto constantemente superada por meio de crises (MARX, 1988, p. 185).

Aqui se reafirma o entendimento de que as crises não são desvios de conduta do capital, mas, pelo contrário, são soluções momentâneas para os obstáculos que o capital encontra no decorrer de seu movimento em busca de valorização. Em $O$ capital, Marx explica que a oscilação para mais ou para menos da taxa de lucro não é reflexo direto da oscilação da taxa de mais-valia. Demonstra que uma 
taxa de mais-valia constante pode expressar uma taxa de lucro decrescente, ou seja, "a mesma taxa de mais-valia com grau constante de exploração do trabalho expressar-se-ia assim em uma taxa decrescente de lucro" [...] (MARX, 1988, p. 154). Isso ocorre, pois a variação no volume de capital constante influencia no volume do capital global. A taxa de lucro é expressa na relação entre taxa de mais-valia e capital global. Com o crescimento do volume material do capital constante, “[...] cresce também, ainda que não na mesma proporção, o volume de valor do capital constante e, com isso, o do capital global" (MARX, 1988, p. 154).

O desenvolvimento das forças produtivas reitera um movimento de crescente produtividade. Historicamente, a ciência e a técnica são aplicadas na produção e, por consequência, a produtividade das forças produtivas sociais se eleva ao extremo. A máquina pode produzir cada vez mais com um número cada vez menor de trabalhadores, fato que se reflete na negação de trabalho vivo. O decréscimo no valor do capital variável em relação ao valor do capital constante pode ser observado nesse processo. Sendo a taxa de lucro a relação entre a taxa de mais-valia obtida no final do processo e o capital global adiantado, com o aumento do valor deste, uma mesma taxa de mais-valia constituirá uma taxa de lucro cada vez menor.

[...] mostrou-se, entretanto, como lei do modo de produção capitalista que, com seu desenvolvimento, ocorre um decréscimo relativo do capital variável em relação ao capital constante e, com isso, em relação ao capital global posto em movimento. Isso só quer dizer que o mesmo número de trabalhadores [...] põe em movimento, processa e consome produtivamente ao mesmo tempo uma massa sempre crescente de meios de trabalho [...], portanto, também um capital constante de volume de valor sempre crescente (MARX, 1988, p. 154-5).

Se esse processo se generaliza, a crise está instaurada. Se não há taxa de lucro satisfatória, os pagamentos não podem ser realizados, e o dinheiro se retira de circulação. A insolvência se generaliza, a taxa de lucro geral entra em queda, e a acumulação e a reprodução do capital veem-se interrompidas.

Como demonstra Marx, esse processo não pode ser considerado um acidente ou um mero desvio no desenvolvimento do capitalismo. As crises capitalistas têm de ser vistas como resultados do movimento do próprio capital em sua produção e reprodução. "A tendência progressiva da taxa geral de lucro a cair é, portanto, apenas uma expressão peculiar ao modo de produção capitalista para o desenvolvimento progressivo da força produtiva social de trabalho" (MARX, 1988, p. 155). 
Marx demonstra teoricamente como o capitalismo tende a crises temporárias e cíclicas, e essa tendência é demonstrada "a partir da essência do modo de produção capitalista, como uma necessidade óbvia” (MARX, 1988, p. 155). Não se trata da influência de algum elemento exógeno, exterior ao capital, mas de seu próprio movimento. As crises, vistas como reflexo das taxas de lucro em queda, são expressões do modo de existência da produção capitalista e, além disso, expressões de seu modo contraditório de existência.

Quanto à tendência ao declínio da taxa de lucro, Belluzzo (1980, p. 100-1) afirma que:

[...] na perspectiva vislumbrada por Marx, a natureza contraditória do processo de acumulação capitalista manifesta-se fundamentalmente na tendência ao declínio da taxa de lucro, como expressão característica desse regime de produção, não porque o capital demonstre qualquer inclinação a incorrer em rendimentos decrescentes à medida que se acumula, senão, ao contrário, porque sua acumulação envolve obrigatoriamente a potenciação continuada da força produtiva social do trabalho.

Como afirma Belluzzo, a potenciação continuada da força produtiva social do trabalho é necessidade indispensável ao capital para se reproduzir, e, paradoxalmente, é justamente essa necessidade que cria um penoso obstáculo para sua reprodução. O crescimento do valor do capital constante em relação ao capital variável é fenômeno que obedece à lógica do capital de produzir cada vez mais.

O capital é sempre uma potência que produz cada vez em maior quantidade e em menor tempo, mas essa potencialidade esbarra no aumento do valor do capital constante em relação ao valor do capital variável (mesmo que ambos cresçam de forma absoluta), e, com isso, a taxa de lucro é pressionada para baixo.

\section{O EXCESSO DE CAPITAL NA DÉCADA DE 1970: RAIZ DAS CRISES ATUAIS}

Pode-se afirmar que a economia capitalista se encontra em estagnação desde a década de 1970. Para o historiador inglês Eric Hobsbawn, "[...] parece que tal desempenho decorre de uma crise geral da sociedade capitalista, iniciada no final dos anos 1960 e que abriu uma fase de 'crise continuada"' (HоBSBAwm, 1995, p. 393). A crise atual, iniciada em 2008, seria, assim, um dos fenômenos relacionados à longa crise por que passa a economia capitalista. O capitalismo estaria, então, atra- 
vessando um período de dificuldades que já dura mais de trinta anos, no qual há o surgimento de uma série de crises pontuais, caracterizadas como crises financeiras.

Longe de ser o fenômeno recente e quase fortuito retratado pela maioria das análises em curso, que preferem enfocar causas imediatas, além de relacionadas a escolhas de agentes privados e públicos, a crise atual é um processo sistêmico, antigo, cujas raízes remontam à década de 1970. [...] o que começou ali, de fato, foi um período de estagnação dos investimentos, com queda persistente na taxa média de lucro e desvalorização de capital na economia dos Estados Unidos, coordenadora do sistema comercial e financeiro mundial (GRESPAN, 2009, p. 11).

Grespan entende que a crise atual tem como motivação inicial o período da década de 1970. Nesse momento, a economia capitalista mundial estava saindo de um período de grande crescimento, e isso gerou um acúmulo de capital que não conseguia espaço para se realizar. Argumenta que:

Em linhas gerais, o patamar técnico e institucional alcançado durante os trinta anos posteriores à Segunda Guerra Mundial, chamado resumidamente de "fordismo" (com todas as suas variantes e derivações), permitiu crescente incorporação de mão de obra até que novos investimentos levassem à queda da taxa de lucro, e não a seu aumento, como antes (GreSPAN, 2009, p. 14).

Nessa passagem, Grespan corrobora o entendimento de que as crises capitalistas são provenientes do aumento da composição orgânica do capital, consequência da busca pela elevação da capacidade produtiva por meio dos investimentos em capital constante.

Brenner, argumentando na mesma direção, afirma que as raízes da crise atual podem ser encontradas na segunda metade da década de 1960, quando empresas alemãs e japonesas expandiram sua produção e colocaram seus produtos no mercado mundial com preços mais baixos que seus concorrentes. Nesse sentido,

O resultado foi excesso de capacidade e de produção fabril, expresso na menor lucratividade agregada no setor manufatureiro das economias do grupo dos 7 (G-7) como um todo. Os fabricantes com custos altos dos Estados Unidos sofreram originalmente o impacto dessa queda, tendo a lucratividade caído cerca de 40\% no setor fabril e 25-30\% na economia como um todo entre 1965 e 1973. Em 1973, no entanto, tanto o Japão quanto a Alemanha [...] foram obrigados a 
enfrentar custos cada vez maiores, em conseqüência da severa valorização de suas moedas em relação ao dólar que ocorreu no momento da crise monetária internacional e do colapso da ordem de Bretton Woods entre 1971 e 1973. Foi a grande queda de lucratividade dos Estados Unidos, Alemanha, Japão e do mundo capitalista adiantado como um todo - e sua incapacidade de recuperação - a responsável pela redução secular das taxas de acumulação de capital, que são a raiz da estagnação econômica de longa duração ao longo do último quartel de século (BRENNER, 1998, p. 07).

Capacidade produtiva em excesso requer alto nível de desenvolvimento dos meios de produção. Brenner considera que o excesso de capacidade produtiva, vale dizer, o montante de capital constante acumulado, foi responsável por uma compressão dos lucros em escala mundial. Em um ambiente de alta produtividade por parte da indústria, a composição orgânica do capital se torna elevada de tal maneira que os lucros, sendo expressão da relação entre a taxa de mais-valia e o capital global, tendem a cair.

[...] as grandes corporações dos Estados Unidos, Alemanha e Japão que dominavam o setor fabril mundial pareciam ter perspectivas muito melhores de manter e aumentar a lucratividade pelo incremento da competitividade em suas próprias linhas do que pela transferência para outros setores. Elas contavam com grandes volumes de capital empatado já pago em suas próprias linhas; tinham relações antigas com fornecedores e clientes que não podiam ser facilmente reproduzidas em outros ramos; haviam criado, durante longo período, um saber tecnológico especializado, duramente conquistado, que era útil apenas em suas próprias linhas. Assim, durante e após a década de 1970, as corporações dos Estados Unidos, Alemanha e Japão geralmente não largaram suas posições a menos que fossem forçadas a isso, e o resultado foi que havia pouca saída e alívio para o excesso de capacidade fabril (BRENNER, 1998, p. 07).

No sentido de buscar as raízes da crise, Paulani enfatiza uma mudança do regime de acumulação ocorrido na segunda metade do século xx, no qual as empresas se ausentam do setor produtivo para buscar valorização no setor financeiro. Afirma que:

As multinacionais americanas espalhadas na Europa optam por não reinvestir a totalidade de seus lucros na produção, pois as perspectivas de ganho já não eram 
tão boas, mas tampouco enviam o excedente não reinvestido aos Estados Unidos, por conta de uma legislação tributária, à época, considerada muito dura. Esses recursos (eurodólares) começam então a "empoçar" na city londrina, o espaço off shore, também conhecido como euromarket, criado no início dos anos 1950 (Paulani, 2009b, p. 31).

Desses fatos pode-se entender que os rendimentos obtidos no setor produtivo, em vez de serem reinvestidos nesse mesmo setor, são desviados para a busca de valorização em curto prazo nos mercados financeiros. A incapacidade de realizar valor no sistema produtivo, quando a composição orgânica do capital se eleva em relação ao capital global adiantado, faz com que os lucros sejam pressionados para baixo. Nessa situação, o investimento se volta a meios alternativos à valorização, via produção de mercadorias. A busca pelo juro acaba se colocando em primeiro plano, negando a busca pelo lucro.

Para Chesnais (1998b, p. 18), a partir da década de 1970, houve uma queda das taxas de investimento na economia mundial. Não sendo possível sustentar a valorização do capital, foi gerada uma capacidade ociosa no setor produtivo, o que é expressão da elevação extrema de capital constante na produção. O economista francês afirma que, nos últimos trinta anos, o capital procurou outros meios para superar seus limites. Esses meios estão nos mercados financeiros. Entende que a forma escolhida para superar os limites imanentes ao capital foi recorrer à criação de capital fictício.

A criação de capital fictício é um dos instrumentos a que o capital recorre para se sustentar em um ambiente de crise e dificuldade de realizar valor. Mas a crise no setor financeiro da economia não quer dizer que não haja relação com o setor produtivo, local por excelência da criação de valor. Nesse sentido, em uma entrevista sobre a crise da Ásia no ano de 1998, Chesnais (1998a, p. 30) afirma:

A gravidade do processo em curso está ligada ao fato de que, por trás de um episódio aparentemente financeiro, há na verdade uma crise econômica. Ela traduz a dificuldade crescente das empresas [...] para vender as mercadorias produzidas, atender os objetivos de rentabilidade fixados para os investimentos produtivos e, portanto, satisfazer os níveis de rendimentos aos quais os operadores financeiros se habituaram, sobretudo nos Estados Unidos ao longo desta década. 


\section{CONSIDERAÇÕES FINAIS}

Ao tratar da questão da teoria de Marx acerca do fenômeno das crises capitalistas, visa-se tecer alguns comentários que se julga serem pertinentes para compreender o caminho teórico percorrido pelo pensador alemão, pois se julga sua teoria ser instrumento indispensável para a compreensão do capitalismo e seus fenômenos. A crítica à economia política de Marx dispensa o discurso da harmonia do mercado capitalista para demonstrar sua existência contraditória. O capital se movimenta de contradição em contradição, e esta se manifesta de diversas formas na realidade.

Da análise da teoria de Marx depreende-se que as crises capitalistas são momentos de exacerbação das contradições do capital. É nos momentos de crise que fica visível a forma contraditória inscrita no modo de ser do capital, pois esses momentos revelam um conteúdo que realiza na realidade concreta as contradições de forma violenta. Mas as crises, além de expressarem as contradições internas do capital, aparecem como instrumento para solucionar momentaneamente a interrupção do movimento de valorização do capital. Assim, não são acontecimentos fortuitos e exógenos ao capital; são, pois, fenômenos inseparáveis da existência do modo de produção capitalista. Aparecem como manifestação concreta da interrupção da valorização e como solução momentânea para isso, mesmo que a solução dure por um tempo cada vez menor.

\section{REFERÊNCIAS BIBLIOGRÁFICAS}

BeLluzzo, Luiz Gonzaga de Mello. Valor e capitalismo: um ensaio sobre a economia política. São Paulo: Brasiliense, 1980.

BRENner, Robert. A crise emergente do capitalismo mundial: do neoliberalismo à depressão? Outubro, São Paulo, n. 3, p. 07-18, 1998.

Chesnais, François. Crise da Ásia ou do capitalismo? ADUSP, São Paulo, n. 14, p. 29-36, 1998a.

Rumo a uma mudança total dos parâmetros econômicos mundiais dos enfrentamentos políticos e sociais. Outubro, São Paulo, n. 1, p. 07-32, 1998b.

Grespan, Jorge. O negativo do capital. São Paulo: Hucitec, 1998.

. A crise de sobreacumulação. Crítica Marxista, n. 29, p. 11-17, 2009.

Hobsbawn, Eric. A era dos extremos: o breve século XX (1914-1991). São Paulo: Companhia das Letras, 1995 . 
A crise do capitalismo e a importância atual de Marx. Disponível em: $<$ http://www.cartamaior.com.br/templates/materiaMostrar.cfm?materia_id=15253>. Acesso em: 11 abr. 2012.

MARx, Karl. Teorias da mais-valia: história crítica do pensamento econômico. São Paulo: DIFEL, 1980.

Para a crítica da economia política; salário, preço e lucro; o rendimento e suas fontes: a economia vulgar. São Paulo: Abril Cultural, 1982. . O capital: crítica da economia política. São Paulo: Nova Cultural, 1983. O capital: crítica da economia política. São Paulo: Nova Cultural, 1988. . Capítulo VI inédito de O Capital. São Paulo: Centauro, 2004.

Mazzucheldi, Frederico. A contradição em processo. São Paulo: Brasiliense, 1985.

Paulani, L. M. A atualidade da crítica da economia política. Crítica Marxista, São Paulo, n. 10, p.111-121, 2000.

A crise do regime de acumulação com dominância da valorização financeira e a situação do Brasil. Estudos Avançados, v. 23, n. 66, 2009 a. Disponível em: <http://www.scielo.br/scielo.php?script=sci_arttext\&pid=So10340142009000200003\&lng=pt\&nrm=i\&tlng=pt>. Acesso em: 30 abr. 2012.

. Marx, as crises e a "desregulação financeira". mai. 2009b. Disponível em: $<$ http://www.cartamaior.com.br/templates/materiaMostrar.cfm?materia_id=15992>. Acesso em: 30 abr. 2012. 